\title{
Role of acetylcholine and serotonin in novelty processing using an oddball paradigm
}

Citation for published version (APA):

Caldenhove, S., Borghans, L., Blokland, A., \& Sambeth, A. (2017). Role of acetylcholine and serotonin in novelty processing using an oddball paradigm. Behavioural Brain Research, 331, 199-204.

https://doi.org/10.1016/j.bbr.2017.05.031

Document status and date:

Published: 28/07/2017

DOI:

10.1016/j.bbr.2017.05.031

Document Version:

Publisher's PDF, also known as Version of record

Document license:

Taverne

Please check the document version of this publication:

- A submitted manuscript is the version of the article upon submission and before peer-review. There can be important differences between the submitted version and the official published version of record.

People interested in the research are advised to contact the author for the final version of the publication, or visit the DOI to the publisher's website.

- The final author version and the galley proof are versions of the publication after peer review.

- The final published version features the final layout of the paper including the volume, issue and page numbers.

Link to publication

\footnotetext{
General rights rights.

- You may freely distribute the URL identifying the publication in the public portal. please follow below link for the End User Agreement:

www.umlib.nl/taverne-license

Take down policy

If you believe that this document breaches copyright please contact us at:

repository@maastrichtuniversity.nl

providing details and we will investigate your claim.
}

Copyright and moral rights for the publications made accessible in the public portal are retained by the authors and/or other copyright owners and it is a condition of accessing publications that users recognise and abide by the legal requirements associated with these

- Users may download and print one copy of any publication from the public portal for the purpose of private study or research.

- You may not further distribute the material or use it for any profit-making activity or commercial gain

If the publication is distributed under the terms of Article $25 \mathrm{fa}$ of the Dutch Copyright Act, indicated by the "Taverne" license above, 
Research report

\title{
Role of acetylcholine and serotonin in novelty processing using an oddball paradigm
}

\author{
S. Caldenhove ${ }^{1}$, L.G.J.M. Borghans ${ }^{1}$, A. Blokland, A. Sambeth* \\ Department of Neuropsychology and Psychopharmacology, Maastricht University, Maastricht, The Netherlands
}

\section{A R T I C L E I N F O}

\section{Keywords:}

Novelty oddball

Biperiden

Acute tryptophan depletion

Acetylcholine

Serotonin

P3a

\begin{abstract}
A B S T R A C T
The processing of novel stimuli is known to take place in the hippocampus and frontal cortex, and is influenced by the cholinergic system. This ability is crucial to help detect changes in the environment and adapt behaviour accordingly. Previous research has shown that acetylcholine (ACh) can interact with serotonin (5-HT) at the hippocampal level, which may have consequences for cognitive functioning. However, little is known about the exact nature of this ACh and 5-HT interaction as well their possible interactive effects on novelty processing.

We investigated the interactive role of ACh and 5-HT in novelty processing in healthy young participants. Levels of these neurotransmitters were manipulated with the muscarinic M1 antagonist biperiden, and with acute tryptophan depletion (ATD). Participants received either placebo, biperiden, ATD, or a combination of both in a double-blind cross-over design. Auditory event-related potentials (ERPs) were recorded while a novelty oddball task was presented.

Our results showed that biperiden affected ERP components considered to reflect attentional mechanisms; it increased the P50 amplitude and decreased that of the P200. Furthermore, a decrease of N100 amplitude by ATD was reversed by biperiden. The treatments did not affect the mismatch negativity (MMN) component, which is elicited when a deviant stimulus is presented in a sequence of repetitive stimuli. Importantly, biperiden decreased the amplitude of the ERP component related to novelty processing (P3a).

The current study's results did not reveal an interactive effect of ACh and 5-HT on novelty processing. However, the data do suggest that ACh is involved in novelty processing and that it influences basic stimulus processing, without affecting sound-discrimination accuracy.
\end{abstract}

\section{Introduction}

In everyday life it is essential to appropriately and efficiently process novel stimuli and events, as well as to distinguish them from known stimuli. The novelty response is elicited when a stimulus is new, unexpected or unpredictable, and it can be visualized measuring the event-related potential (ERP) component P3a [1]. This component, also called novelty P3, can be elicited by both active and passive tasks such as oddball tasks. The novelty P3 reaches maximal amplitude at frontal and central midline electrode positions and peaks around $250-300 \mathrm{~ms}$ after onset of a stimulus [2,3]. It is thought that the novelty P3 is generated by the frontal lobe and hippocampus [4-7].

A related ERP is the mismatch negativity (MMN), an auditory ERP that is generated by the brains automatic response to a discriminable auditory change. This component reflects an automatic process that detects changes in ongoing auditory stimulation [2]. The MMN is generated in both auditory cortices, where a change detection process takes place unconsciously. This information is then transferred to the frontal cortex where the information may be perceived consciously [8]. The MMN is obtained by extracting the ERP of standard stimuli from deviant stimuli and can be seen 150-250 ms after stimulus onset [9].

The cholinergic system is involved in cognitive processes such as memory and attention [10]. More specifically it is known that degeneration of cholinergic neurons in the basal forebrain lead to memory and other cognitive problems [11]. Cholinergic challenges have widely been used to mimic memory impairments in healthy volunteers and to test the effectiveness of possible treatments for memory impairment [12]. The role of acetylcholine (ACh) is associated with different cognitive processes, with some suggesting it is involved in learning and memory [e.g., [13]], whereas others suggest a role of ACh in attentional processes [e.g., [14]]. Studies using scopolamine as a cholinergic antagonist showed involvement of ACh in novelty processing. When using an active oddball task after the administration of scopolamine, the amplitude of the novelty P3 was reduced [15].

\footnotetext{
* Corresponding author at: Department of Neuropsychology and Psychopharmacology, Maastricht University, PO Box 616, 6200 MD Maastricht, The Netherlands.

E-mail address: anke.sambeth@maastrichtuniversity.nl (A. Sambeth).

${ }^{1}$ These authors contributed equally.
} 
However scopolamine did not affect the MMN component after a passive oddball task [16].

As scopolamine is a nonselective anticholinergic drug, administration also leads to central and peripheral side effects; a more selective drug might be preferable over scopolamine to be used as a deficit model. Biperiden is a selective muscarinic antagonist that has a more preferable profile than the traditionally muscarinic antagonist scopolamine. Biperiden has a higher affinity for the M1 and M4 muscarinic receptors compared to the other receptor types [17]. Cholinergic receptors can be found throughout the body, but the M1 receptor is mainly located in the cerebral cortex and hippocampus [18]. In line with this assumption, we found that biperiden impaired verbal memory performance, but also affected novelty processing $[19,20]$. Based on these findings the effects of biperiden have been linked to cognitive deficits in schizophrenia [e.g., [21]].

Serotonin (5-HT) is also related to learning and memory. A method that has been used as a model for lowering 5-HT is acute tryptophan depletion (ATD) [22]. It is presumed that ATD impairs cognition by lowering central 5-HT levels [23, but see 24] and actually has been shown to impair long-term memory many times [see [25] for a pooled analysis]. ATD lowers brain 5-HT levels by depleting tryptophan, a precursor of 5-HT, but alternative pathways, such as the kynurenine pathway, might be involved as well $[24,26]$.

Previous animal research showed that ACh and 5-HT interact at an anatomical and neurochemical level $[27,28]$. Previous research has shown that ACh can interact with 5-HT at the hippocampal level, affecting cognitive functions [29]. However, little is known about the exact nature of this ACh and 5-HT interaction as well their possible interactive effects on novelty processing. A recent study combined biperiden and ATD while measuring EEG and showed interactions in their effect on the P3a amplitude in relation to an episodic memory task, suggesting that an impairment in novelty processing led to the memory impairments seen after especially the biperiden treatment [30]. However the exact nature of this interaction still remains unclear. To further investigate the interaction between ACh and 5-HT on attention and novelty processing biperiden and ATD were combined in this study.

The aim of the current study was to assess the effects of biperiden, ATD and a combination of both in a novelty EEG paradigm. The effects were tested in a mismatch negativity and novelty P3 during a novelty oddball task. Given the interaction previously shown for P3a amplitude in an episodic task, we hypothesized that the P3a would be reduced more after the combined treatment as compared to treatment with either biperiden or ATD alone.

\section{Methods}

\subsection{Participants}

Seventeen healthy participants (7 male, 10 female; mean age of 22.4 years $(\mathrm{SD}=3.0$, range $=19-29)$ ) completed the experiment, who were recruited from Maastricht University via advertisements. All participants had a body mass index between 18.5 and 30 and were in good health as determined by a screening protocol including a standard medical questionnaire on physical and mental health, and a medical examination. This examination included measurements of blood pressure and pulse rate, a resting electrocardiogram (ECG), urine samples for drug screen and pregnancy test, and blood samples for haematology and biochemistry.

Participants were excluded in case of past or current cardiac, hepatic, renal, pulmonary, neurological, gastrointestinal, or haematological illness; current, past, or having a first-degree relative with psychiatric illness; pregnancy; lactation; and presence of any sensory or motor deficits which could be expected to affect test performance. Furthermore, use of medication other than oral contraceptives, use of recreational drugs later than 2 weeks before start of the study, and excessive alcohol consumption ( $>20$ alcohol beverages per week) also lead to exclusion from this study.

All participants signed an informed consent form prior to participating in the study and received a financial reward for their participation. This study was approved by the Medical Ethics Committee of Maastricht University and performed in accordance with the 1964 Declaration of Helsinki.

\subsection{Treatment and design}

In order to induce ATD, participants consumed a protein drink without tryptophan $5 \mathrm{~h}$ before EEG measurements were taken. The drink consisted of $100 \mathrm{~g}$ gelatin (Solugel P) provided by PB Gelatins in Tessenderlo, Belgium which was mixed with $200 \mathrm{ml}$ tap water. Previous studies in which an ATD drink with an identical mixture was used, have shown its impairing effects on cognition [e.g., [31]]. Additionally, it has consistently been found that this treatment leads to a $70-75 \%$ decrease in human plasma tryptophan levels [31-33]. The placebo treatment consisted of a drink containing the same composition, with the addition of $1.21 \mathrm{~g}$ L-tryptophan. ATD and placebo drinks had an identical taste.

One hour before the EEG recording, biperiden hydrochloride (Akineton ${ }^{\circ}$ instant release) was administered orally. Capsules were purchased from Laboratorio Farmaceutico S.I.T. in Mede, Italy and contained $2 \mathrm{mg}$ biperiden, which is within the range of recommended doses for this drug. Former studies have found that $2 \mathrm{mg}$ of orally administered biperiden impairs cognitive performance in healthy (older) adults $[34,35]$.

The study was carried out according to a double-blind, placebocontrolled, 4-way cross-over design. The treatment order (biperiden, ATD, a combination, or placebo) was balanced over 4 test days and separated by a washout period of at least 7 days. Each participant received the medication in a unique order.

\subsection{Procedure}

It should be noted that this study was part of a larger experiment assessing the interactive role of ACh and 5-HT in cognitive processing [30]. Only the results of the novelty oddball task are reported here.

After enrolment in the study, the participants first performed a training session in order to familiarize them with the procedure and minimize learning effects. The day before a test day, participants were not allowed to consume alcohol, and on the test day itself caffeine intake was not allowed.

Each test day started with an assessment of general status and the participant filling in the questionnaires. Subsequently, participants received either the ATD protein drink or the placebo drink. Participants were then allowed read a book or study while they waited. Three hours after intake of the drink, the capsule containing either biperiden or a placebo was administered. In the hour following, the participants were allowed to have a low-protein lunch containing protein free bread, jam, a tomato, an apple, and some caffeine-free soda. Participants were prepared for EEG recording and after this hour, the EEG recording and cognitive testing started.

\subsection{EEG recording and stimuli}

An EEG cap was used containing 32 electrodes according to the international 10-20 system (Jasper, 1958). The reference and ground were placed at the linked mastoids and at the FPz position within the cap, respectively. Eye movements were detected by horizontal and vertical electro-oculogram (EOG) recordings. Before electrode attachment, the positions were cleaned with alcohol and slightly scrubbed with a gel in order to provide an impedance of less than $5 \mathrm{kOhm}$. Both EEG and EOG were filtered between 0.01 and $100 \mathrm{~Hz}$ and sampled at $1000 \mathrm{~Hz}$. 
In the novelty oddball task, three types of auditory stimuli were presented while the participants watched a silent cartoon and were instructed to ignore the stimuli: frequent standard, infrequent deviant and infrequent novel stimuli. The standard and deviant stimuli consisted of $750 \mathrm{~Hz}$ and $500 \mathrm{~Hz}$ tones, respectively, with two upper harmonic components (1000 and 1500; 1500 and $2250 \mathrm{~Hz}$ ). The intensity of the first and second harmonic components was lowered compared to the fundamental by 3 and $6 \mathrm{~dB}$, respectively. The novel stimuli contained three stimulus categories of 20 different sounds, namely human, animal, and mechanical sounds. The infrequent deviant and novel stimuli were each presented randomly in $12.5 \%$ of the trials. All sounds were presented for a duration of $300 \mathrm{~ms}$ with 10-ms rise and fall times and a $1000 \mathrm{~ms}$ onset asynchrony was used. Stimuli were presented with an average intensity of $70 \mathrm{~dB}$.

\subsection{Analysis}

\subsubsection{EEG analysis}

All EEG data were analyzed using BrainVision Analyzer 2.0 (Brain Products GmhB, Gilching, Germany). Offline, the data were visually inspected to check for artefacts. EOG activity was filtered out of the EEG using the data of the VEOG channel and trials in which movement artefacts occurred were excluded from analysis. The EEG signal was filtered using a high-pass filter at $1 \mathrm{~Hz}$ (12 dB slope) and a low-pass filter at $30 \mathrm{~Hz}$ (12 dB slope). The EEG fragments within an epoch of $100 \mathrm{~ms}$ before stimulus onset and $1000 \mathrm{~ms}$ after stimulus onset were averaged to extract the ERP components, using the $100 \mathrm{~ms}$ pre-stimulus as baseline.

For each of the four treatment conditions, averages were calculated separately for the three stimulus types (standard, deviant, novel). Next, grand averages were made from which the following obligatory ERP components were determined: P50 (60-90 ms), N100 (90-140 ms), and P200 (130-240 ms). Furthermore, difference waves were calculated by subtracting the averages of the standard stimulus from the averages of the deviant and novel stimuli types. The grand averages of these difference waves were used to determine the following components: MMN (100-190 ms) and P3a (180-300 ms).

\subsubsection{Statistical analysis}

All data were analyzed using the SPSS for Windows (version 21; SPSS Inc, Chicago, IL, USA). The Fz, FCz, and $\mathrm{Cz}$ electrodes were used because these channels elicited the largest ERP responses in these types of tasks [2]. The maximum amplitudes and latencies of the obligatory P50, N100, and P200 components and those of the MMN and P3a from the difference waves were analyzed using a $2 \times 2 \times 3$ repeated measures ANOVA. The two-treatment conditions biperiden (2 levels: yes or no biperiden) and ATD (2 levels: yes or no ATD) and Electrode (3 levels: $\mathrm{Fz}, \mathrm{FCz}$, and $\mathrm{Cz}$ ) were entered as within subject factors. In case of interaction effects, simple effects were examined. A significance level of $\alpha=.05$ was used throughout and Bonferroni correction was used for post hoc tests.

\section{Results}

One participant was excluded from analysis due to incomplete data. Sixteen participants were included in the final analysis.

Overall, latencies were not found to be significantly affected by the treatment conditions. Some Treatment $\mathrm{x}$ Electrode effects were found randomly throughout the data, which were considered spurious and were not reported on in the following section.

\subsection{Obligatory ERP responses}

Fig. 1 shows that the deviant and novel sounds elicited larger amplitudes than standards in the placebo condition, in line with normal findings in the novelty oddball paradigm. Fig. 2 shows the effects of the

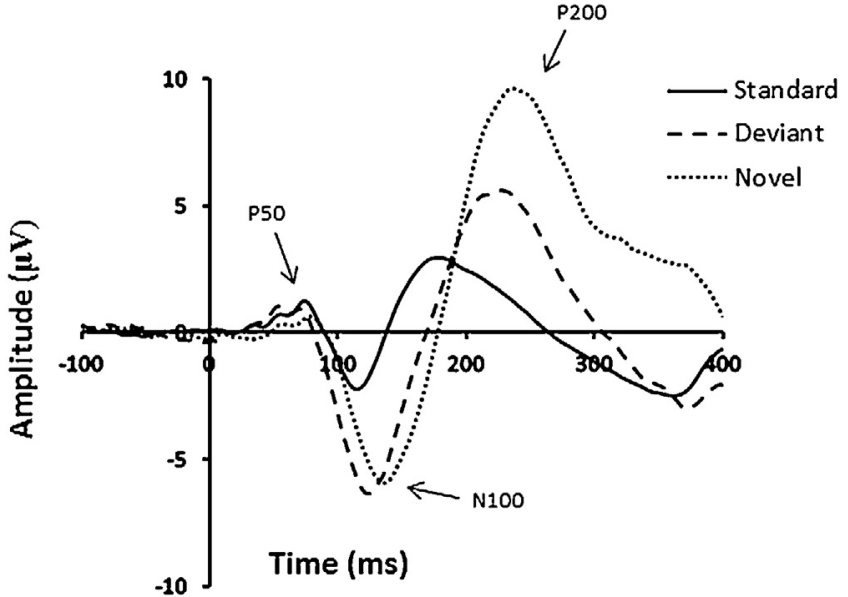

Fig. 1. ERP responses to the standard, deviant, and novel stimuli of the placebo condition (shown here: $\mathrm{Cz}$ electrode). Generally, deviant and novel sounds elicited larger amplitudes than standards.

four treatment conditions on P50, N100 and P200 amplitudes of the standard stimuli.

The $2 \times 2 \times 3$ analysis revealed that treatment with biperiden significantly increased the P50 amplitude $(F(1,15)=8.264$, $p=0.012)$ and decreased the P200 amplitude $(F(1,15)=5.364$, $p=0.035)$. ATD treatment did not result in significant effects on the amplitude of these components (P50 $(F(1,15)=1.835, p$ 0.196; P200 $(F(1,15)=4.326, p=0.055))$, although the latter did show a trend towards significance. An ATD*biperiden interaction effect was found on the amplitude of the $\mathrm{N} 100(F(1,15)=6.315, p=0.024)$. An analysis of simple effects revealed that the combination of ATD and biperiden lead to a significant increase of the $\mathrm{N} 100$ amplitude $(F(1,15)=4.912$, $p=0.043$ ), while this was not the case for participants only treated with $\operatorname{ATD}(F(1,15)=2.982, p=0.105)$. No interaction was found on the P50 $(F(1,15)=2.624, p=0.126)$ or the P200 $(F(1,15)=0.198$, $p=0.663)$.

\subsection{Difference waves}

In Fig. 3 the difference waves of the placebo group are presented. Generally, the ERP components in the novel-standard difference wave have larger amplitudes than those in the deviant-standard difference wave. Fig. 4 visualizes the effects of the four treatment conditions on the P3a amplitude of the novel-standard difference score.

None of the treatments significantly affected MMN amplitudes of the deviant-standard difference scores (ATD $(F(1,15)=3.493$, $p=0.081)$; biperiden $(F(1,15)=1.405), p=0.254)$; ATD*biperiden $(F(1,15)=0.547, p=0.471))$ or the novel-standard difference scores (ATD $(F(1,15)=0.269, p=0.612$; biperiden $(F(1,15)=0.995$, $p=0.334)$; ATD*biperiden $(F(1,15)=0.403, p=0.535)$. However, treatment with biperiden significantly reduced the P3a amplitude of the novel-standard difference score $(F(1,15)=15.205, p=0.001)$. Treatment with ATD did not significantly change P3a amplitude $(F(1$, $15)=2.164, p=0.162$ ) nor was an ATD*biperiden interaction effect evident $(F(1,15)=1.047, p=0.322)$. No significant results were found for the P3a amplitude of the deviant-standard difference score (ATD $(F(1,15)=1.113, p=0.308)$; biperiden $(F(1,15)=4.542$, $p=0.050)$; ATD*biperiden $(F(1,15)=0.919, p=0.353)$, although treatment with biperiden did result in a trend towards significance.

\section{Discussion}

Based on the interaction of ACh and 5-HT on cognitive functioning we investigated whether such an interaction also exists in relation to human novelty processing. We showed that biperiden, but not ATD, 

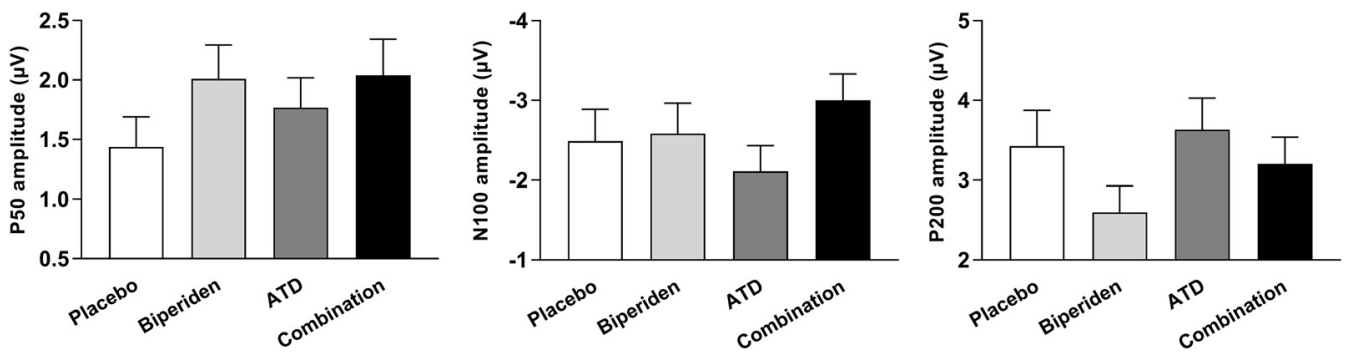

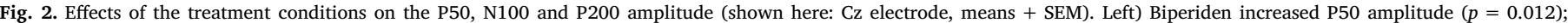

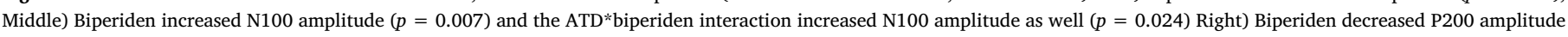
$(p=0.035)$.

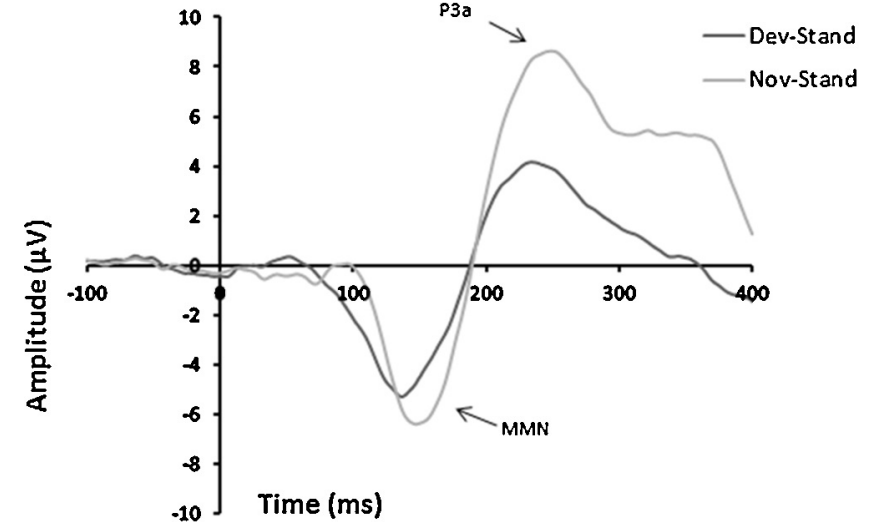

Fig. 3. Deviant-standard and novel-standard difference waves of the placebo condition (shown here: $\mathrm{Cz}$ electrode). The MMN and P3a components of the deviant-standard difference score were smaller in amplitude than the MMN and P3a components of the novel-standard difference score.

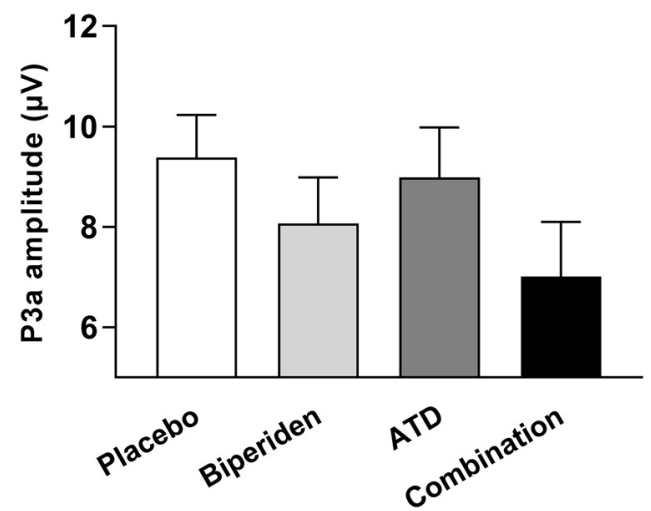

Fig. 4. Effects of the treatments conditions on P3a amplitude of the novel-standard difference score (shown here: $\mathrm{Cz}$ electrode (means + SEM). Biperiden reduced P3a amplitude $(p=0.001)$.

dampened the processing of novel sounds. This was reflected by a reduced amplitude of the $\mathrm{P} 3 \mathrm{a}$ component, the novelty response of the brain. None of the treatments had an effect on the MMN, a component related to sound-discrimination accuracy and sensory memory. Basic stimulus processing was assessed by measuring the P50, N100 and P200 components. We found that biperiden increased the amplitude of the P50 and N100 peaks, whereas P200 amplitude was decreased. An interaction effect was found only on the N100, but not on any of the other recorded ERP signals. These data suggest that M1 antagonism affects basic stimulus processing and leads to a reduction in novelty processing, and that there is neither an effect, nor an interaction with 5HT.

\section{1. $P 3 a$}

In this study, biperiden significantly reduced P3a amplitude, while treatment with ATD did not. Our findings corroborate the notion that ACh is involved in attentional processes [14]. By lowering ACh levels, the neural response to novel sounds decreases. This is in line with the findings of Borghans and colleagues [30], who found disrupted novelty processing after biperiden in an episodic memory task.

Like biperiden, scopolamine is a muscarinic cholinergic receptor antagonist. Scopolamine is considered the golden standard for inducing memory deficits and therefore, it has been used more often than biperiden to study the role of ACh in memory, including novelty processing. After treatment with scopolamine, several studies have shown a reduced amplitude of the novelty P3 [15,36-39, but see 40]. However, these studies used an active novelty oddball task, whereas here a passive task was used. In active oddball tasks participants have to respond to target stimuli, requiring more attentional effort. This generally elicits a parietal P3b peak linked to context updating and working memory function, instead of the frontocentral P3a reflecting novelty and attentional processing $[41,42]$.

Using a passive oddball paradigm, Klinkenberg, Blokland, Riedel and Sambeth [20] studied the effects of biperiden and rivastigmine, the latter increasing ACh levels, on auditory ERPs like the P3a in healthy young volunteers. In contrast with their hypothesis, biperiden did not affect the P3a. However, treatment with rivastigmine did enhance P3a amplitude, which was reversed by biperiden. The authors suggest that the P3a may not be influenced by drugs acting on M1 receptors, but rather on another cholinergic receptor, i.e., M2-M5 or nicotinic receptors. As scopolamine is not specific for the M1 receptor, its actions on the P3a can also be explained using this line of reasoning. On the other hand, our results do point to an involvement of M1-receptors in the processing of novel sounds, since biperiden reduced P3a amplitude.

We expected ATD to also affect the novelty P3, as previous studies with ATD have shown to impair cognitive processes by lowering central levels of 5-HT [43,44,e.g.,45]. Unfortunately, not much literature exists on the effects of ATD on the P3a, specifically. One study by Ahveninen and colleagues [46] measured the effects of tryptophan depletion on EEG and MEG responses, but did not find an effect on the P3a. However, the paradigm used in their study was different from the novelty oddball paradigm and was not geared towards eliciting robust P3a responses, but rather towards limiting N100/N200b contamination of the MMN response. It could be disputed whether ATD is an effective method for lowering 5-HT neurotransmission [24], or whether it mediates another chemical process in the brain. It is beyond the scope of this paper discussing the possible mechanism of action of ATD here.

\section{2. $M M N$}

In line with our expectations, no effect was found of biperiden on the MMN. ATD also did not affect this component. The auditory MMN is considered to be an index of sound-discrimination accuracy and auditory sensory memory [47]. Previous EEG studies in which a passive 
oddball task was used have found inconsistent results on the MMN after using scopolamine $[16,48]$. After the administration of biperiden the MMN was not affected [20].

Contrary to our hypothesis, the current study's results did not show ATD to affect the MMN. Previous studies that applied ATD have found the MMN to be modulated by a 5 -HT decrease [49,50], although the authors do report that the MMN has overlapping subcomponents reflecting different phases of detection and orienting to novel stimuli. Additionally, Kahkonen, Makinen, Jaaskelainen, Pennanen, Liesivuori and Ahveninen [50] explained that the enhancement of MMN seen after ATD in their study could be the result of confounding effects of N1 modulation. The MMN increase would then actually be an enhanced N1 response, and not a genuine MMN increase.

\subsection{Obligatory responses}

Similar to the effects on novelty processing, it seems that ACh has a role in modulating the processes which are related to the obligatory responses, while 5-HT does not. Our results showed that biperiden increased the amplitude of the P50 peak, decreased the P200 amplitude, and reversed a decrement in the N100 amplitude leading to a larger amplitude of the N100, with no statistically significant effects of ATD. The P50, N100, and P200 components reflect pre-attentive, early attentive, and late attentive processing mechanisms, respectively [51,52].

The majority of studies that have used passive or active oddball paradigms using scopolamine $[15,38,39,48]$ have not found effects on the N100 and/or P200 amplitude, except for Curran and colleagues [36] who showed that scopolamine decreased the N100 and P200 amplitudes. Klinkenberg and colleagues [20], who used biperiden in a passive oddball task, also did not find effects on the N100 and P200 amplitudes. Effects of drugs on the P50 have rarely been investigated; however, the existing literature is in line with our findings $[20,48]$. It should be noted that differences exist between the aforementioned studies with regard to i.e., recording methods, data analysis, drug dosage, and means of administration. For this reason, it is difficult to directly compare the previous study's results to our results. The study by Klinkenberg and colleagues [20] is most comparable to the current study. While they have not found effects of biperiden on the N100 and P200, it was able to reverse an enhanced P3a amplitude. It could be possible that biperiden has a different effect on early and late attentional mechanisms. This pattern is also evident in our data, since we found that biperiden increased the P50 and N100 (i.e. early attentive) amplitudes and decreased the P200 and P3a (i.e. late attentive) amplitudes.

The exact role of 5-HT in attentional processes has yet to be unravelled. There are indications that 5 -HT is related to learning and memory processes $[25,53]$, but the role of 5 -HT on the neural correlates of early attentional processes has rarely been investigated. Similar to this study's results, a number of EEG studies using other methods of ATD to examine auditory evoked potentials have not been able to find effects of lowering central serotonergic levels on the P50 [54], or the N100/P200 [55,56]. However, evidence also exists that shows ATD does affect the P50 and N100 by suppressing their amplitudes [57].

\subsection{Interactive effects of biperiden and ATD}

Little is yet known about the interactive effects of ACh and 5-HT on cognition. We expected to see an interaction effect of the two neurotransmitter systems on the novelty P3, based on findings from previous animal research [see 27,58]. The results did not confirm our expectations. Additionally, there was no evidence of such an interaction on other measures of cognitive processing (i.e., P50/N100/P200; MMN). It may therefore be assumed that in humans, lower levels of both ACh and 5-HT neurotransmission do not affect processing of novel stimuli, auditory sensory memory, or any of the early stages of memory processing to a larger extent than when either neurotransmission of either ACh or 5-HT is lowered.

Next to the difficulties in translating animal to human research, there could be a number of reasons why no interaction effect was found in this study. Firstly, the combination of biperiden and ATD used in the current study may not have been effective in establishing an interaction of the two neurotransmitters on cognitive function. Whereas biperiden blocks ACh neurotransmission by antagonizing the M1 receptor, ATD likely reduces general brain 5-HT levels and is not receptor-specific [59]. Even though a selective challenge was combined with a global challenge in this study, both methods are assumed to act on different neurotransmitters in the brain. Since both methods have shown to be able to impair memory performance separately (ATD [e.g.,25,43]; biperiden [e.g.,20,34]) a stronger impairment may have been expected when combining treatments. For future research, it would be interesting to look at methods able to lower levels of 5-HT neurotransmission at the same cortical sites biperiden has its effect.

Secondly, while there is ample evidence for the effectiveness of biperiden in creating a cholinergic memory deficit [see 60], evidence for the effects of ATD on 5-HT is still limited. As mentioned previously, ATD may not have been effective in lowering cortical 5-HT neurotransmission. More research on this topic is needed.

Finally, it may also be the case that lowering levels of ACh and 5-HT at the same time does not cause an interactive effect on the cognitive functions measured, at least in humans. More studies are needed to draw a conclusion on this matter.

\section{Conclusions}

We found that ACh, but not 5-HT is involved in novelty processing and basic stimulus processing. Participant's sound-discrimination accuracy seems to be unaffected by lower central levels of these neurotransmitters. No interaction between ACh and 5-HT neurotransmission was found on the components measured. Since event-related potentials form an indirect method of measuring treatment effects, an interaction effect of both neurotransmitter systems cannot be fully excluded. However, there is ample evidence providing support for the notion that an interaction between serotonergic and cholinergic systems can be detected using electrophysiological recording techniques in general [27][see 27], and more specifically there exists some support for this interactive role in human EEG studies [e.g., [39]]. More research is needed to better understand the possible interaction between ACh and 5 -HT on attention and memory.

\section{Funding}

This study was supported by the Netherlands Organization for Scientific Research, grant number 451-07-011.

\section{References}

[1] J. Polich, J.R. Criado, Neuropsychology and neuropharmacology of P3a and P3b, Int. J. Psychophysiol. 60 (2) (2006) 172-185.

[2] C.C. Duncan, R.J. Barry, J.F. Connolly, C. Fischer, P.T. Michie, R. Naatanen, J. Polich, I. Reinvang, C. Van Petten, Event-related potentials in clinical research: guidelines for eliciting, recording, and quantifying mismatch negativity, P300, and N400, Clin. Neurophysiol. 120 (11) (2009) 1883-1908.

[3] J. Polich, Updating P300: an integrative theory of P3a and P3b, Clin. Neurophysiol. 118 (10) (2007) 2128-2148.

[4] R. Knight, Contribution of human hippocampal region to novelty detection, Nature 383 (6597) (1996) 256-259.

[5] D. Kumaran, E.A. Maguire, The dynamics of hippocampal activation during encoding of overlapping sequences, Neuron 49 (4) (2006) 617-629.

[6] D.E. Linden, The p300: where in the brain is it produced and what does it tell us? Neuroscientist 11 (6) (2005) 563-576.

[7] S. Yamaguchi, Neural network for novelty processing, Suppl. Clin. Neurophysiol. 57 (2004) 635-641.

[8] R. Naatanen, T. Kujala, C. Escera, T. Baldeweg, K. Kreegipuu, S. Carlson, C. Ponton, The mismatch negativity (MMN) - a unique window to disturbed central auditory processing in ageing and different clinical conditions, Clin. Neurophysiol. 123 (3) 
(2012) 424-458.

[9] M. Sams, P. Paavilainen, K. Alho, R. Naatanen, Auditory frequency discrimination and event-related potentials, Electroencephalogr. Clin. Neurophysiol. 62 (6) (1985) 437-448.

[10] M.E. Hasselmo, The role of acetylcholine in learning and memory, Curr. Opin. Neurobiol. 16 (6) (2006) 710-715.

[11] R.T. Bartus, R.L. Dean, M.J. Pontecorvo, C. Flicker, The cholinergic hypothesis: a historical overview, current perspective, and future directions, Ann. N. Y. Acad. Sci. 444 (1985) 332-358.

[12] U. Ebert, W. Kirch, Scopolamine model of dementia: electroencephalogram findings and cognitive performance, Eur. J. Clin. Invest. 28 (11) (1998) 944-949.

[13] A. Easton, V. Douchamps, M. Eacott, C. Lever, A specific role for septohippocampal acetylcholine in memory? Neuropsychologia 50 (13) (2012) 3156-3168.

[14] I. Klinkenberg, A. Sambeth, A. Blokland, Acetylcholine and attention, Behav. Brain Res. 221 (2) (2011) 430-442.

[15] S.B. Brown, N.J. van der Wee, M.S. van Noorden, E.J. Giltay, S. Nieuwenhuis, Noradrenergic and cholinergic modulation of late ERP responses to deviant stimuli, Psychophysiology 52 (12) (2015) 1620-1631.

[16] E. Pekkonen, I.P. Jaaskelainen, S. Kaakkola, J. Ahveninen, Cholinergic modulation of preattentive auditory processing in aging, Neuroimage 27 (2) (2005) 387-392.

[17] C.C. Perez, I.D. Tobar, E. Jimenez, D. Castaneda, M.B. Rivero, J.L. Concepcion, M.A. Chiurillo, R. Bonfante-Cabarcas, Kinetic and molecular evidences that human cardiac muscle express non-M2 muscarinic receptor subtypes that are able to interact themselves, Pharmacol. Res. 54 (5) (2006) 345-355.

[18] I. Klinkenberg, A. Blokland, The validity of scopolamine as a pharmacological model for cognitive impairment: a review of animal behavioral studies, Neurosci. Biobehav. Rev. 34 (8) (2010) 1307-1350.

[19] A. Sambeth, W.J. Riedel, I. Klinkenberg, S. Kahkonen, A. Blokland, Biperiden selectively induces memory impairment in healthy volunteers: no interaction with citalopram, Psychopharmacology (Berl) 232 (11) (2015) 1887-1897.

[20] I. Klinkenberg, A. Blokland, W.J. Riedel, A. Sambeth, Cholinergic modulation of auditory processing, sensory gating and novelty detection in human participants, Psychopharmacology (Berl) 225 (4) (2013) 903-921.

[21] S.P. Carruthers, C.T. Gurvich, S.L. Rossell, The muscarinic system, cognition and schizophrenia, Neurosci. Biobehav. Rev. 55 (2015) 393-402.

[22] S.N. Young, R.O. Pihl, F.R. Ervin, The effect of altered tryptophan levels on mood and behavior in normal human males, Clin. Neuropharmacol. 11 (Suppl. 1) (1988) S207-S215.

[23] T. Klaassen, W.J. Riedel, N.E. Deutz, A. van Someren, H.M. van Praag, Specificity of the tryptophan depletion method, Psychopharmacology (Berl) 141 (3) (1999) 279-286.

[24] E.L. van Donkelaar, A. Blokland, L. Ferrington, P.A. Kelly, H.W. Steinbusch, J. Prickaerts, Mechanism of acute tryptophan depletion: is it only serotonin? Mol. Psychiatry 16 (7) (2011) 695-713.

[25] A. Sambeth, A. Blokland, C.J. Harmer, T.O. Kilkens, P.J. Nathan, R.J. Porter J.A. Schmitt, B. Scholtissen, S. Sobczak, A.H. Young, W.J. Riedel, Sex differences in the effect of acute tryptophan depletion on declarative episodic memory: a pooled analysis of nine studies, Neurosci. Biobehav. Rev. 31 (4) (2007) 516-529.

[26] P.J. Kennedy, A.P. Allen, A. O’Neill, E.M.M. Quigley, J.F. Cryan, T.G. Dinan, G. Clarke, Acute tryptophan depletion reduces kynurenine levels: implications for treatment of impaired visuospatial memory performance in irritable bowel syndrome, Psychopharmacology (Berl.) 232 (8) (2015) 1357-1371.

[27] J.C. Cassel, H. Jeltsch, Serotonergic modulation of cholinergic function in the central nervous system: cognitive implications, Neuroscience 69 (1) (1995) 1-41.

[28] H. Jeltsch-David, J. Koenig, J.C. Cassel, Modulation of cholinergic functions by serotonin and possible implications in memory: general data and focus on 5-HT(1A) receptors of the medial septum, Behav. Brain Res. 195 (1) (2008) 86-97.

[29] C.K. Lieben, A. Blokland, A. Sik, E. Sung, P. van Nieuwenhuizen, R. Schreiber, The selective 5-HT6 receptor antagonist Ro4368554 restores memory performance in cholinergic and serotonergic models of memory deficiency in the rat, Neuropsychopharmacology 30 (12) (2005) 2169-2179.

[30] L.G.J.M. Borghans, A. Blokland, A. Sambeth, Effects of biperiden and acute tryptophan depletion and their combination on verbal word memory and EEG, Psychopharmacology (Berl) 234 (7) (2017) 1135-1143.

[31] A. Sambeth, W.J. Riedel, D.E. Tillie, A. Blokland, A. Postma, J.A. Schmitt, Memory impairments in humans after acute tryptophan depletion using a novel gelatinbased protein drink, J. Psychopharmacol. 23 (1) (2009) 56-64.

[32] E.A. Evers, D.E. Tillie, F.M. van der Veen, C.K. Lieben, J. Jolles, N.E. Deutz, J.A. Schmitt, Effects of a novel method of acute tryptophan depletion on plasma tryptophan and cognitive performance in healthy volunteers, Psychopharmacology (Berl) 178 (1) (2005) 92-99.

[33] D.S. Stenbæk, H.S. Einarsdottir, T. Goregliad-Fjaellingsdal, G.M. Knudsen, V.G. Frokjaer, S.G. Hasselbalch, Evaluation of acute tryptophan depletion and sham depletion with a gelatin-based collagen peptide protein mixture, Eur. Neuropsychopharmacol. 26 (1) (2016) 147-149.

[34] E. Wezenberg, R.J. Verkes, B.G.C. Sabbe, G.S.F. Ruigt, W. Hulstijn, Modulation of memory and visuospatial processes by biperiden and rivastigmine in elderly healthy subjects, Psychopharmacology (Berl) 181 (3) (2005) 582-594.

[35] A. Sambeth, W.J. Riedel, I. Klinkenberg, S. Kähkönen, A. Blokland, Biperiden selectively induces memory impairment in healthy volunteers: no interaction with citalopram, Psychopharmacology (Berl) 232 (11) (2015) 1887-1897.

[36] H.V. Curran, P. Pooviboonsuk, J.A. Dalton, M.H. Lader, Differentiating the effects of centrally acting drugs on arousal and memory: an event-related potential study of scopolamine, lorazepam and diphenhydramine, Psychopharmacology (Berl) 135 (1) (1998) 27-36.

[37] K.J. Meador, D.W. Loring, R.J. Adams, B.R. Patel, H.C. Davis, E.J. Hammond, Central cholinergic systems and the P3 evoked potential, Int. J. Neurosci. 33 (3-4) (1987) 199-205.

[38] K.J. Meador, D.W. Loring, H.C. Davis, K.D. Sethi, B.R. Patel, R.J. Adams, E.J. Hammond, Cholinergic and serotonergic effects on the P3 potential and recent memory, J. Clin. Exp. Neuropsychol. 11 (2) (1989) 252-260.

[39] K.J. Meador, D.W. Loring, N. Hendrix, M.E. Nichols, R. Oberzan, E.E. Moore, Synergistic anticholinergic and antiserotonergic effects in humans, J. Clin. Exp. Neuropsychol. 17 (4) (1995) 611-621.

[40] K.J. Meador, D.W. Loring, G.P. Lee, H.S. Taylor, D.R. Hughes, D.S. Feldman, In vivo probe of central cholinergic systems, J. Gerontol. 43 (6) (1988) M158-M162.

[41] M.D. Comerchero, J. Polich, P3a and P3b from typical auditory and visual stimuli, Clin. Neurophysiol. 110 (1) (1999) 24-30.

[42] E. Donchin, Presidential address 1980. Surprise!.Surprise? Psychophysiology 18 (5) (1981) 493-513.

[43] W.J. Riedel, T. Klaassen, N.E. Deutz, A. van Someren, H.M. van Praag, Tryptophan depletion in normal volunteers produces selective impairment in memory consolidation, Psychopharmacology (Berl) 141 (4) (1999) 362-369.

[44] M. Rangel-Gomez, M. Meeter, Neurotransmitters and novelty: a systematic review, J. Psychopharmacol. 30 (1) (2016) 3-12.

[45] A.G. Fischer, T. Endrass, I. Goebel, M. Reuter, C. Montag, C. Kubisch, M. Ullsperger, Interactive effects of citalopram and serotonin transporter genotype on neural correlates of response inhibition and attentional orienting, Neuroimage 116 (2015) 59-67.

[46] J. Ahveninen, S. Kahkonen, S. Pennanen, J. Liesivuori, R.J. Ilmoniemi, I.P. Jaaskelainen, Tryptophan depletion effects on EEG and MEG responses suggest serotonergic modulation of auditory involuntary attention in humans, Neuroimage 16 (4) (2002) 1052-1061.

[47] S.J. Luck, E.S. Kappenman, The Oxford Handbook of Event-Related Potential Components, OUP, USA, 2013

[48] E. Pekkonen, J. Hirvonen, I.P. Jaaskelainen, S. Kaakkola, J. Huttunen, Auditory sensory memory and the cholinergic system: implications for Alzheimer's disease, Neuroimage 14 (2) (2001) 376-382.

[49] S. Kahkonen, J. Ahveninen, Combination of magneto- and electroencephalography in studies of monoamine modulation on attention, Methods Find. Exp. Clin. Pharmacol. 24 (Suppl. C) (2002) 27-34.

[50] S. Kahkonen, V. Makinen, I.P. Jaaskelainen, S. Pennanen, J. Liesivuori, J. Ahveninen, Serotonergic modulation of mismatch negativity, Psychiatry Res. 138 (1) (2005) 61-74.

[51] M. Lijffijt, S.D. Lane, S.L. Meier, N.N. Boutros, S. Burroughs, J.L. Steinberg, F.G. Moeller, A.C. Swann, P50, N100, and P200 sensory gating: relationships with behavioral inhibition, attention, and working memory, Psychophysiology 46 (5) (2009) 1059-1068.

[52] N.N. Boutros, O. Korzyukov, B. Jansen, A. Feingold, M. Bell, Sensory gating deficits during the mid-latency phase of information processing in medicated schizophrenia patients, Psychiatry Res. 126 (3) (2004) 203-215.

[53] A. Meneses, 5-HT system and cognition, Neurosci. Biobehav. Rev. 23 (8) (1999) 1111-1125.

[54] C. Mann, R.J. Croft, K.E. Scholes, A. Dunne, B.V. O’Neill, S. Leung, D. Copolov, K.L. Phan, P.J. Nathan, Differential effects of acute serotonin and dopamine depletion on prepulse inhibition and p50 suppression measures of sensorimotor and sensory gating in humans, Neuropsychopharmacology 33 (7) (2008) 1653-1666.

[55] A.E. Massey, V.R. Marsh, R.H. McAllister-Williams, Lack of effect of tryptophan depletion on the loudness dependency of auditory event related potentials in healthy volunteers, Biol. Psychol. 65 (2) (2004) 137-145.

[56] S. Debener, A. Strobel, K. Kurschner, C. Kranczioch, J. Hebenstreit, A. Maercker, A. Beauducel, B. Brocke, Is auditory evoked potential augmenting/reducing affected by acute tryptophan depletion? Biol. Psychol. 59 (2) (2002) 121-133.

[57] J. Ahveninen, I.P. Jaaskelainen, S. Pennanen, J. Liesivuori, R.J. Ilmoniemi, S. Kahkonen, Auditory selective attention modulated by tryptophan depletion in humans, Neurosci. Lett. 340 (3) (2003) 181-184.

[58] T. Steckler, A. Sahgal, The role of serotonergic-cholinergic interactions in the mediation of cognitive behaviour, Behav. Brain Res. 67 (2) (1995) 165-199.

[59] S.D. Hood, C.J. Bell, D.J. Nutt, Acute tryptophan depletion. Part I: rationale and methodology, Aust. N. Z. J. Psychiatry 39 (7) (2005) 558-564.

[60] A. Blokland, A. Sambeth, J. Prickaerts, W.J. Riedel, Why an M1 antagonist could be a more selective model for memory impairment than scopolamine, Front. Neurol. 7 (2016) 167. 